\title{
Occult papillary microcarcinoma of the thyroid-a potential pitfall of fine needle aspiration cytology?
}

\author{
H R Harach, E Saravia Day, S B Zusman
}

\begin{abstract}
The use of fine needle aspiration cytology detected papillary carcinoma in two patients with multinodular goitre measuring $0.7 \mathrm{~cm}$ and $0.9 \mathrm{~cm}$ in diameter, respectively. Like most of the cases from previous large series, the tumours progressed slowly as shown by absence of enlarged glands on surgical exploration and no clinical signs of metastasis after two and five years of follow up. This study shows that aspiration cytology can detect a virtually harmless occult papillary carcinoma that will oblige patients to have surgery. This very occasional "pitfall" of fine needle aspiration should not preclude this well known beneficial method from being used in the management of thyroid disease.
\end{abstract}

Fine needle aspiration (FNA) cytology is an accurate and selective method for diagnosing thyroid disease. Its application reduces the need for surgery with the attendant risks to patients, and it is cost effective. ${ }^{12}$ Occult papillary carcinomas of the thyroid occur frequently in systematic necropsy studies and may also be discovered incidentally during surgery for an unrelated thyroid lesion..$^{3-7}$ These tumours may present clinically with regional metastases, but their prognosis is excellent and not life threatening. ${ }^{367} \mathrm{We}$ report two patients with occult papillary carcinoma of the thyroid incidentally detected by FNA that, in our opinion, led to virtually unnecessary surgical intervention.

Pathology Service, Dr A Onativia Endocrinology and Metabolism Hospital, Salta, Argentina

H R Harach

S B Zusman

Department of Surgery, Dr A Onativia

Endocrinology and

Metabolism Hospital,

Salta, Argentina

E Saravia Day

Correspondence to: Dr H Ruben Harach, Department of Pathology, University of Wales Colleg Cardiff CF4 4XN

Accepted for publication 23 October 1990

\section{Case reports}

Two female patients aged 43 and 25 years, respectively, presented with a lump in the neck. After palpation multinodular goitre was diagnosed. A thyroid scintigram showed irregular radioiodine uptake in nodular areas from both lobes. Routine laboratory analyses and studies of thyroid function were within the normal ranges. Thyroid FNA was performed on both patients. The right thyroid lobes were chosen because they showed the dominant nodules as described in our previous study. ${ }^{2}$ Smears showed epithelial cells individually and arranged in sheets and clusters containing nuclei that were irregular in shape. They also showed overlapping, prominent nucleoli, and sometimes nuclear cytoplasmic inclusions and grooving (figs 1 and 2). A cytological diagnosis of papillary carcinoma was made and the patients underwent subtotal thyroidectomy.

Frozen sections of thyroid were cut at 3$5 \mathrm{~mm}$ intervals and showed multiple, well demarcated colloid nodules of various sizes. The right lobes from both thyroids also showed a whitish hard $0.9 \mathrm{~cm}$ nodule and a $0.7 \mathrm{~cm}$ cystic lesion, respectively, that histologically corresponded to papillary microcarcinomas of the thyroid. Surgical exploration of bilateral cervical lymph nodes showed no abnormalities.

Diagnoses of multinodular goitre and papillary microcarcinoma were confirmed on permanent sections from both patients. One of the tumours was mainly composed of trabeculae and microfollicles (fig 1); the cystic tumour showed mainly papillary and follicular structures (fig 2). In both cases the neoplastic cells showed irregular and sometimes pale nuclei, prominent nucleoli, some nuclear cytoplasmic inclusions and grooving (figs 1 and 2). The capsule of the cystic carcinoma showed an occasional psammoma body, as well as haemorrhagic changes and an inflammatory reaction probably due to the needle pass (fig 2). The patients were well and free of disease five years and two years after diagnosis.

\section{Discussion}

A histological diagnosis of papillary microcarcinoma according to the WHO classification was made in both cases as the tumours were smaller than $1 \mathrm{~cm}$ in diameter. ${ }^{8}$ Nuclear grooves and cytoplasmic inclusions are diagnostic cytological variables that have also been described in aspirates from clinically manifest papillary carcinomas. ${ }^{9}$ The term occult papillary carcinoma is also used for tumours smaller than $1.5 \mathrm{~cm}$ in diameter, ${ }^{356}$ but nowadays it is preferred for tumours with no clinical signs ${ }^{10}$ as in our cases.

The cytological features of clinically evident papillary carcinomas smaller than $1.5 \mathrm{~cm}$ in diameter have been described. ${ }^{11} \mathrm{~A}$ fortuitous finding of an occult focus (probably larger than $1 \mathrm{~cm}$ ) of a multicentric papillary carcinoma by FNA has been reported. Thyroid scan reevaluation showed this to be a cold nodule. ${ }^{12}$ The two occult papillary carcinomas incidentally detected by FNA would not have been detected by thyroid scintigraphy due to their small size. This is not unexpected as the prevalence of these tumours is high in systematic necropsy studies ${ }^{3-5}$ with an incidence 
Figure 1 Papillary microcarcinoma with dominant trabecular component infiltrating the thyroid capsule

(haematoxylin and eosin). Inset: aspirate showing neoplastic cells with irregular nuclei containing prominent nucleoli, grooving (large arrow) and cytoplasmic inclusion (small arrow)

(Papanicolaou).

Figure 2 Cystic papillary microcarcinoma with dominant papillary component. At the interface between tumour and surrounding thyroid tissue there are two

haemorrhagic lakes with a histiocytic reaction, possibly as a consequence of traumatic needle pass (haematoxylin and eosin). Left inset: neoplastic cells with irregular nuclei showing prominent nucleoli and grooving (arrows) (Papanicolaou). Right inset: nuclear cytoplasmic inclusion in a neoplastic cell close to a cluster of non-neoplastic cells (MayGrünwald-Giemsa).

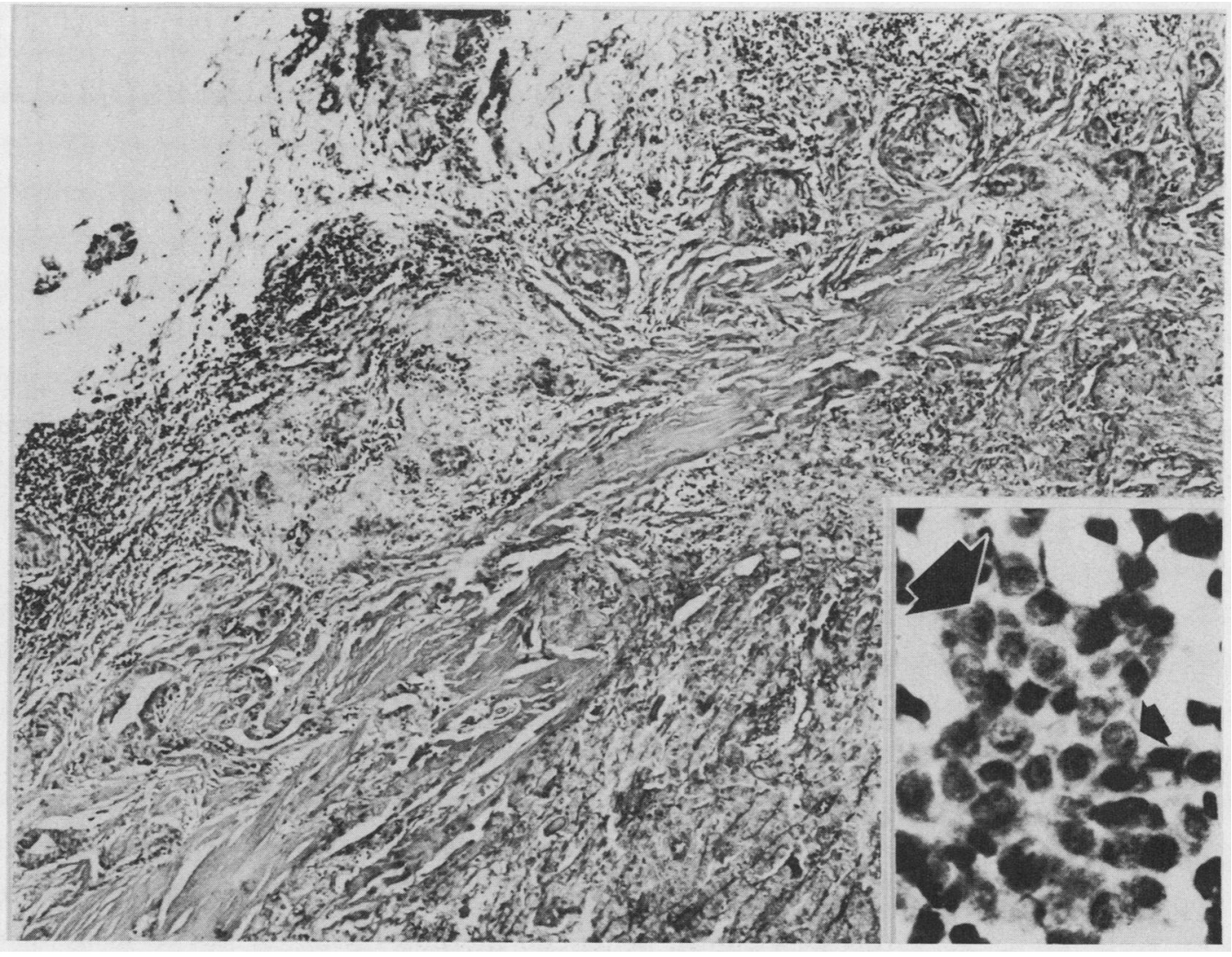

of up to $36 \%$, a figure much lower than would be expected if thyroids had been examined only histologically. ${ }^{5}$ Most occult papillary carcinomas are smaller than $1 \mathrm{~cm}$ in diameter but their size range is not comparable in different series because the sections have been examined by different workers. ${ }^{5}$

Whether these tumours would have become clinically manifest is not known. They were

intrathyroidal as no lymph node disease was found during surgical exploration and no clinical signs of metastases were present during the two to five years of follow up. Most occult papillary carcinomas found by accident are confined to the thyroid according to large surgical and necropsy series. ${ }^{3671314}$ The prevalence of regional micrometastases was $16 \%$ in a series of systematic lymph node

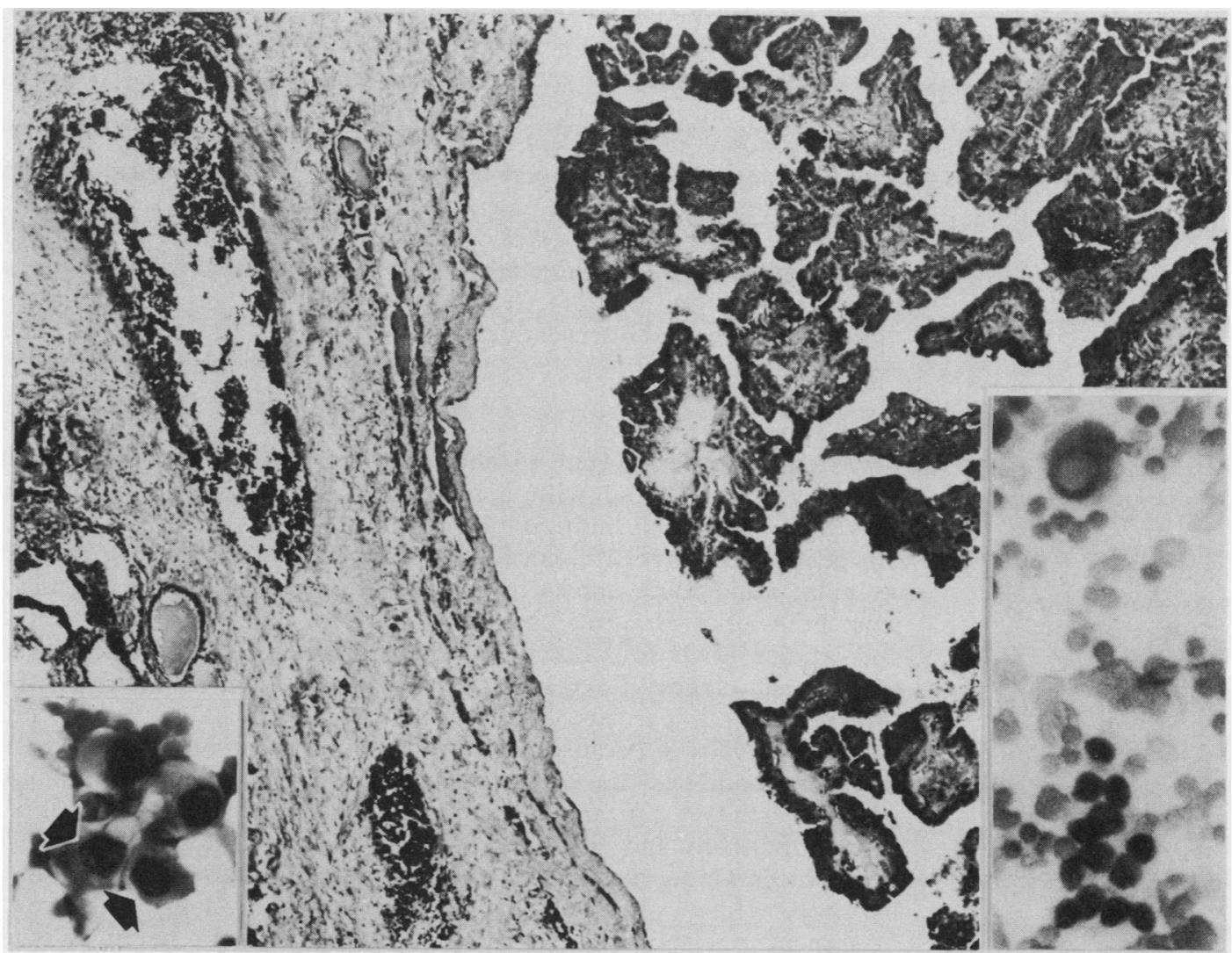


dissections. ${ }^{13}$ Papillary carcinomas up to $1.5 \mathrm{~cm}$ in diameter with regional lymph nodes metastases, as well as clinically manifest larger intrathyroidal papillary carcinomas, have an excellent prognosis and are not life threatening. ${ }^{3671315}$ Distant metastases from occult papillary carcinomas are practically non-existent, as shown in a large necropsy series $^{13}$ and, when clinically manifest, are sometimes unremarkable. ${ }^{16-18}$

In conclusion, FNA may eventually detect a harmless occult papillary microcarcinoma that will unavoidably lead to surgery as happened in our cases. In our series this "pitfall" occurred twice in 1758 aspirates $(0 \cdot 1 \%)$ which should not interfere with the known beneficial use of FNA cytology in the management of thyroid disease. ${ }^{12}$

1 Hamberger B, Gharib H, Melton CJ, Goellner JR, Zinsmeister AR. Fine needle aspiration biopsy of thyroid nodules. Impact on thyroid practice and cost of care. Am J Med 1982;73:381-4.

2 Harach HR. Usefulness of fine needle aspiration of the thyroid in an endemic goiter region. Acta Cytol 1989; 33:31-5.

3 Sampson RJ. Prevalence and significance of occult thyroid cancer. In DeGroot IJ, ed Radiation-associated thyroid carcinoma. New York: Grune and Stratton, 1977:137-53.

4 Fukunaga FH, Yatani R. Geographic pathology of occult thyroid carcinomas. Cancer 1975;36:1095-9.

5 Harach HR, Franssila KO, Wasenius VM. Occult papillary carcinoma of the thyroid. A "normal" finding in Finland. A systematic autopsy study. Cancer 1985;56:531-8.

6 Hubert JP, Kiernan PD, Beahrs OH, McConahey WM Woolner LB. Occult papillary carcinoma of the thyroid. Arch Surg 1980;115:394-8.

7 Vickery AL Jr, Wang CA, Walker AM. Treatment of intrathyroidal papillary carcinoma of the thyroid. Cancer 1987;60:2587-95.

8 Hedinger C, Williams ED, Sobin LH. Histological typing of thyroid tumours. International histological classification of thyroid tumours. International histological

9 Shurbaji MS, Gupta PK, Frost JK. Nuclear grooves: a useful criterion in the cytopathologic diagnosis of papillary carcinoma. Diagn Cytopathol 1988;4:91-4.

10 Vickery AL Jr, Carcangiu ML, Johannessen JV, SobrinhoSimoes M. Papillary carcinoma. Semin Diagn Pathol 1985;2:90-100.

11 Schmid KW, Lucciarini P, Ladurner D, Zechmann W, Hofstadter F. Papillary carcinoma of the thyroid gland. Analysis of 94 cases with preoperative fine needle aspiration cytologic examination. Acta Cytol 1987;31:591-4.

12 Beecham JE. Coexistent disease as a complicating factor in the fine needle aspiration diagnosis of papillary carcinoma of the thyroid. Acta Cytol 1986;30:435-8.

13 Sampson RJ, Oka H, Key CR, Buncher CR, Iijima $S$. Metastases from occult thyroid carcinoma. An autopsy study from Hiroshima and Nagasaki, Japan. Cancer 1970;25:803-11.

14 Sampson RJ, Key CR, Buncher CR, Iijima S. Smallest forms of papillary carcinoma of the thyroid. A study of 141 microcarcinomas less than $0.1 \mathrm{~cm}$ in greatest dimension. Arch Pathol 1971;91:334-9.

15 Chen KTK. Minute $(<1 \mathrm{~mm})$ occult papillary thyroid carcinoma with metastasis. Am J Clin Pathol 1989;91:746.

16 Harach HR, Franssila KO. Occult papillary carcinoma of the thyroid appearing as lung metastasis. Arch Pathol Lab Med 1984;108:529-30.

17 Michie HR, O'Bryan-Tear CG, Marsh H, Glazer G. Cerebral metastases from occult papillary carcinoma of the thyroid. Br J Surg 1987;74:647.

18 Allo MD, Christianson W, Koivunen D. Not all "occult" papillary carcinomas are "minimal". Surgery 1988; 104:971-6. 